\title{
PREVALENCE OF HYPERURICEMIA IN PATIENTS OF LOWER BACK PAIN AT DOW UNIVERSITY OF HEALTH SCIENCE CIVIL HOSPITAL KARACHI, PAKISTAN.
}

1. MBBS, FCPS

Assistant Professor Neurosurgery

Dow University of Health Sciences Civil Hospital Karachi.

2. MBBS, FCPS

Assistant Professor Neurosurgery Dow University of Health Sciences Civil Hospital Karachi.

3. MBBS, FCPS

Assistant Professor Neurosurgery Dow University of Health Sciences Civil Hospital Karachi.

4. MBBS, FCPS

Professor Neurosurgery

Dow University of Health Sciences

Civil Hospital Karachi.

5. MBBS, FCPS

Assistant Professor Neurosurgery Dow University of Health Sciences Civil Hospital Karachi.

6. MBBS, FCPS

Assistant Professor Neurosurgery Dow University of Health Sciences Civil Hospital Karachi.

7. MBBS

Resident Neurosurgery

Dow University of Health Sciences, Karachi.

Correspondence Address: Dr. Muhammad Sheraz Raza House No. A139, Block I, North Nazimabad, Karachi. drsherazrazanaqvi@gmail.com

Article received on: 08/02/2019

Accepted for publication: $15 / 08 / 2019$
Ramesh Kumar ${ }^{1}$, Asim Rehmani², Qazi Muhammad Zeeshan ${ }^{3}$, Atiq Ahmed Khan ${ }^{4}$, Shiraz Ahmed Gauri ${ }^{5}$, Muhammad Faiq ${ }^{6}$, Muhammad Sheraz Raza ${ }^{7}$

ABSTRACT... Objectives: In our study we evaluate the hyperuricemia levels in patients presenting to us with the chief complaint of chronic lower back pain and determine the associations with age, gender and radiographic findings. Study Design: Cross sectional study. Setting: Dow University of Health Science Civil Hospital Karachi. Period: From April 2017 to September 2017. Material \& Methods: Patients with lower back pain of a duration longer than three months and between the ages of 18 and 70 years were included. A complete history and physical examination was done for all the patients including relevant laboratory, radiographic and anthropometric measurements. The neurosurgeon also assessed the patient's lower back pain and associated findings in the lower limbs. The patients also underwent radiographic evaluations via X-rays and Magnetic resonance imaging. Data were analyzed using IBM SPSS statistical software version 20 . We considered a $p$ value of $<0.05$ to be statistically significant. Results: The final study population consisted of $n=110$ patients of which $n=54$ were males and $n=56$ were females. Of the total patient population of the study $n=31(28.18 \%)$ had increased serum uric acid and had nearly equal incidence in males and females $(27.77 \%$ and $28.57 \%$ respectively). The highest incidence of hyperuricemia was found patients between 26 and 60 years of age. In our study $n=22$ patients did not have any comorbid condition while joint pain was found in $n=24$ patients ( $p$-value of $<0.05$ ) of these patients they suffered from pain in their knees and tarsal joints. Lumbar disc prolapse was found in $n=21$ patients ( $p$-value of $<0.05$ ), lumbar disc degeneration was found in $n=16$ patients ( $p$-value of $<0.0579$ ). Furthermore, disc space narrowing was found in $n=27$ patients having a $p$-value of $<0.05$. Conclusion: According to the results of our study hyperuricemia is found in one of every four with low back pain. There is a variable association between comorbid conditions and hyperuricemia. While an equal association is found between gender and hyperuricemia. There is also a strong association of hyperuricemia with joint space narrowing and lumbar disc narrowing of the lumbar vertebrae and it augments degenerative spondylolisthesis.

Key words: $\quad$ Hyperuricemia, Low Back Pain, Serum Uric Acid, Spinal Gout.

Article Citation: Kumar R, Rehmani A, Zeeshan QM, Khan AA, Gauri SA, Faiq M, Raza MS. Prevalence of hyperuricemia in patients of lower back pain at Dow University of Health Science Civil Hospital Karachi, Pakistan. Professional Med J 2020; 27 (3):506-510. DOI: 10.29309/TPMJ/2020.27.3.3294

\section{INTRODUCTION}

More than $80 \%$ of the people experience chronic low back pain in their lifetime. ${ }^{1}$

This chronic condition presents a significant economic cost and disability-adjusted life years for the patients. Low back pain can may radiate towards the lower limbs and co-present with joint pain. This pain could be due to hyperuricemia, which results in inflammation and joint pain. Hyperuricemia is defined as abnormally high levels of serum uric acid levels, which might result due to inadequacies in protein metabolism.
The normal range of serum uric acid levels is 3.4 to $7.2 \mathrm{mg} / \mathrm{dl}$ (200 to $430 \mathrm{umol} / \mathrm{L}$ ) for men and 2.4 to $6.1 \mathrm{mg} / \mathrm{dl}$ (140 to $360 \mathrm{umol} / \mathrm{L}$ ) for women. ${ }^{2,3}$

Ten percent of patients with hyperuricemia also develop gout which is deposition of monosodium urate crystals in and around large joints. The prevalence of gout and its associated illnesses and complications is high in patients over 50 years of age and is found to be more common in the male population. ${ }^{4,5}$

Increasing age, diet and lifestyle and comorbid 
conditions are associated with increased prevalence of gout. ${ }^{6,7}$

Gout rarely involves the axial skeleton, and spinal gout is associated with osseous erosions, compression of the spinal cord and degeneration of the lumbar spinal disc which leads to chronic lower back pain. ${ }^{8}$ It involved the intervertebral disc, paraspinal soft tissues, sacroiliac joints and posterior spinal elements. ${ }^{9,10}$

The radiographic analysis is done using magnetic resonance imaging (MRI) on T1 and T2 weighted images. ${ }^{11}$

In our study, we evaluate the hyperuricemia levels in patients presenting to us with the chief complaint of chronic lower back pain and determine the associations with age, gender and radiographic findings. Our study rationale is to evaluate the hyperuricemia levels in patients presenting to us with the chief complaint of chronic lower back pain and determine the associations with age, gender and radiographic findings.

\section{MATERIAL \& METHODS}

The type of study is a cross-sectional study conducted for a period of 6 months duration at a large tertiary care hospital in Karachi, Pakistan, from April 2017 to September 2017. The sampling technique utilized was convenience sampling to recruit a total of 110 patients. A duly informed consent form was signed by all the patients participating in the study, and the hospital ethics committee approved the study. Patients with lower back pain of a duration longer than three months and between the ages of 18 and 70 years were included in our study.

All the patients underwent a complete history and physical examination and inquired about comorbid conditions such as diabetes, ischemic heart diseases, tuberculosis, chronic renal failure, hepatitis and asthma. The patients were also assessed for obesity by measuring their body mass index levels. The neurosurgeon also assessed the patient's lower back pain noting any associated radicular leg pain and joint pain experienced in the lower limbs. The patients also underwent radiographic evaluations via $\mathrm{X}$-rays and Magnetic resonance imaging. These modalities were used to examine the lumbosacral spine, disc enlargement, disc degeneration, and narrowing of the joint spaces between vertebrae among others.

The patients underwent routine laboratory investigations including serum uric acid levels. We considered uric acid levels of 3.4 to $7.2 \mathrm{mg} /$ $\mathrm{dL}$ as normal for males and 2.4 to $6.1 \mathrm{mg} / \mathrm{dl}$ as normal for the female population. Levels above the aforementioned normal ranges were considered as elevated. We analyzed the data using IBM SPSS statistical software version 20. For categorical variables such as age, gender, joint pain, disc degeneration etcetera frequencies and percentages were used. Chi-square test and Fischer's exact test were used to evaluate the association between various diseases and degenerations of the lumbosacral spine with serum uric acid levels. We considered a $p$ value of $<0.05$ to be statistically significant.

\section{RESULTS}

The final study population consisted of $n=110$ patients of which $n=54$ were males and $n=56$ were females. Of the total population $n=14$ were between the ages of 18 and 25 years, $n=83$ were between the ages of 25 and 60 years and $n=13$ were over 60 years of age. Of the total patient population $n=31(28.18 \%)$ had increased levels of serum uric acid and had nearly equal incidence in males and females $(27.77 \%$ and $28.57 \%$ respectively).

The highest incidence of hyperuricemia was found patients between 26 and 60 years of age. In our study $n=22$ patients did not have any comorbid condition while joint pain was found in $n=24$ patients ( $p$-value of $<0.05$ ) of these patients they suffered from pain in their knees and tarsal joints. Lumbar disc prolapse was found in $n=21$ patients ( $p$-value of $<0.05$ ), lumbar disc degeneration was found in $n=16$ patients ( $p$-value of $<0.0579$ ). Furthermore, disc space narrowing was found in $\mathrm{n}=27$ patients having a $\mathrm{p}$-value of $<0.05$. Refer to Tables-I \& II. 


\begin{tabular}{|l|c|c|c|}
\hline \multicolumn{1}{|c|}{ Variable } & $\begin{array}{c}\text { Serum Uric } \\
\text { Acid Levels }\end{array}$ & $\begin{array}{c}\text { Fre- } \\
\text { quency }\end{array}$ & $\begin{array}{c}\text { Per- } \\
\text { centage }\end{array}$ \\
\hline Gender & Elevated & 15 & $27.77 \%$ \\
\hline Male & Normal & 39 & $72.22 \%$ \\
\hline & Elevated & 16 & $28.57 \%$ \\
\hline Female & Normal & 40 & $71.42 \%$ \\
\hline Age group & Elevated & 6 & $42.85 \%$ \\
\hline $18-25$ years & Normal & 8 & $57.14 \%$ \\
\hline & & & \\
\hline $26-60$ years & Elevated & 21 & $25.30 \%$ \\
\hline & Normal & 62 & $74.69 \%$ \\
\hline 60 years and & Elevated & 4 & $30.76 \%$ \\
\hline above & Normal & 9 & $69.23 \%$ \\
\hline
\end{tabular}

Table-I. Patient demographic and other variables of the study population.

\begin{tabular}{|l|c|c|c|}
\hline $\begin{array}{l}\text { Patient Presentation } \\
\text { Signs and Symptoms }\end{array}$ & $\begin{array}{c}\text { Fre- } \\
\text { quency }\end{array}$ & $\begin{array}{c}\text { Per- } \\
\text { centage }\end{array}$ & P-Value \\
\hline Joint pain & $24 / 31$ & $77.41 \%$ & $<0.05$ \\
\hline Lumbar disc prolapse & $21 / 31$ & $67.74 \%$ & $<0.05$ \\
\hline Disc space narrowing & $27 / 31$ & $87.09 \%$ & $<0.05$ \\
\hline Disc degeneration & $16 / 31$ & $51.61 \%$ & $0<0.05$ \\
\hline
\end{tabular}

Table-II. Patient presentation and specific signs and symptoms of our study population.

\section{DISCUSSION}

Hyperuricemia refers to raised serum uric acid levels, which occurs due to defective metabolism of protein. The normal serum ranges of uric acid levels for men is between 3.4 and $7.2 \mathrm{mg} / \mathrm{dl}$ and 2.4 to $6.1 \mathrm{mg} / \mathrm{dl} \mathrm{for} \mathrm{women.} \mathrm{It} \mathrm{is} \mathrm{found} \mathrm{to} \mathrm{be} \mathrm{associated}$ with diseases such as cardiovascular diseases, alcohol consumption, genetic factors, metabolic syndrome and dietary factors. Along with these other comorbid conditions such as diuresis and renal diseases also shows a positive associated with hyperuricemia. ${ }^{6,7,13,14}$ Hyperuricemia usually manifests itself as gout and patients present with pain in large joints of the limbs. In our study, we considered hyperuricemia as a cause of back pain and explored its associations. According to the results of our study, we found a prevalence of $31 \%$ of hyperuricemia in patients with lower chronic back pain, which suggests that increasing levels of uric acid is associated with lower back pain especially when it comes to aggravating the pain for the patients or in spinal gout. We did not find any difference between gender and association of hyperuricemia with back pain. In our study, $21.56 \%$ belonged to an age group that is between 26 to 60 years of age. According to Weaver et al. they reported a higher prevalence of gout in higher age group. ${ }^{15}$ According to the results of our study we found a variable relationship between low back pain and hyperuricemia, with patients occupation, comorbid conditions such as hypertension, diabetes, tuberculosis, asthma, chronic renal failure, vitamin D3 deficiency, ischemic heart disease and obesity, which is also correlated by a study by Rukmini et al who were not able to find any difference between gout and age groups and comorbid conditions. ${ }^{16}$ The presentation of patients with joint pain was associated significantly with hyperuricemia and $77.41 \%$ of the patient population presented to us with a complaint of pain in the joints of the lower limb such as metatarsophalangeal and knee joints. This is quite similar to the findings of a study by Rukmini et al, and is explained by the presence of gouty arthritis in these patients that often leads to the development of joint pain. ${ }^{16,17}$

In our study we included radiographic investigations such as X-rays and MRI's when evidence has showed the computed tomography or CT-scan to be more precise for diagnosis. This step was taken in consideration of the financial constraints of the patients. The patients underwent radiographic imaging of the lumbosacral spine as it is reported to be helpful in the diagnosis of gout. ${ }^{18,19}$ In our study $87.09 \%$ patients had lumbosacral space narrowing on MRI scans and suffered from hyperuricemia, which is similar to the study by Bloch et al. ${ }^{3} \mathrm{~A}$ study done by Michael et al. explores the association of joint pain with narrowing of joint space. ${ }^{20}$ In our study, we have shown that hyperuricemia is associated with an aggravation of chronic low back pain. Through MRI findings it is discovered that hyperuricemia can speed up degenerative spondylolisthesis. There is a need to conduct further large scale studies to make the findings concrete. The primary 
limitation of this presented study is the smaller sample size and that the study was conducted at a single large urban tertiary care hospital.

\section{CONCLUSION}

According to the results of our study hyperuricemia is found in one of every four with low back pain. There is a variable association between comorbid conditions and hyperuricemia. While an equal association is found between gender and hyperuricemia. There is also a strong association of hyperuricemia with joint space narrowing and lumbar disc narrowing of the lumbar vertebrae and it augments degenerative spondylolisthesis. Copyright@ 15 Aug, 2019.

\section{REFERENCES}

1. Freburger JK, Holmes GM, Agans RP, Jackman AM, Darter JD, Wallace AS, Castel LD, Kalsbeek WD, Carey TS. The rising prevalence of chronic low back pain. Archives of internal medicine. 2009 Feb 9;169(3):251-8.

2. Boss GR, Seegmiller JE. Hyperuricemia and gout: classification, complications and management. New England Journal of Medicine. 1979 Jun 28;300(26):145968.

3. Bloch C, Hermann G, Yu TF. A radiologic reevaluation of gout: a study of 2,000 patients. American Journal of Roentgenology. 1980 Apr 1;134(4):781-7.

4. Akram M, Usmanghani K, ALI SS, AKHTAR N, QAISER $\mathrm{J}$, Asif HM, SHAH P, SAEED T. Prevalence of gout in Gadap town, Karachi community, Pakistan. African Journal of Biotechnology. 2011 Aug 1;10(40):7893-5.

5. Smith EU, Diaz-Torne C, Perez-Ruiz F, March LM. Epidemiology of gout: an update. Best Practice \& Research Clinical Rheumatology. 2010 Dec 1;24(6):81127.

6. Choi HK, Mount DB, Reginato AM. Pathogenesis of gout. Annals of internal medicine. 2005 Oct 4;143(7):499-516.

7. Arromdee E, Michet CJ, Crowson CS, O'Fallon WM, Gabriel SE. Epidemiology of gout: is the incidence rising?. The Journal of rheumatology. 2002 Nov 1;29(11):2403-6.
8. Igbinedion $\mathrm{BE}$, Akhigbe $\mathrm{A}$. Correlations of radiographic findings in patients with low back pain. Nigerian medical journal: journal of the Nigeria Medical Association. 2011 Jan;52(1):28.

9. Popovich T, Carpenter JS, Rai AT, Carson LV, Williams HJ, Marano GD. Spinal cord compression by tophaceous gout with fluorodeoxyglucose-positron-emission tomographic/MR fusion imaging. American journal of neuroradiology. 2006 Jun 1;27(6):1201-3.

10. Kelly J, Lim C, Kamel M, Keohane C, O'Sullivan M. Topacheous gout as a rare cause of spinal stenosis in the lumbar region: Case report. Journal of Neurosurgery: Spine. 2005 Feb 1;2(2):215-7.

11. Hsu CY, Shih TT, Huang KM, Chen PQ, Sheu JJ, Li YW. Tophaceous gout of the spine: MR imaging features. Clinical radiology. 2002 Oct 1;57(10):919-25.

12. Aarsand AK, Sandberg S. How to achieve harmonisation of laboratory testing-the complete picture. Clinica chimica acta. 2014 May 15;432:8-14. Doi: 10.1016/j.cca.2013.12.005. [Epub ahead of print].

13. Roddy E, Doherty M. Gout. Epidemiology of gout. Arthritis research \& therapy. 2010 Dec 1;12(6):223.

14. Keenan RT, Pillinger MH. Hyperuricemia, Gout, and Cardiovascular Disease. Bulletin of the NYU hospital for joint diseases. 2009 Jul 1;67(3).

15. Weaver AL (2008) Epidemiology of gout. Cleve Clin J Med 75 Suppl 5:S9-12.

16. Konatalapalli RM, Demarco PJ, Jelinek JS, Murphey M, Gibson M, Jennings B, Weinstein A. Gout in the axial skeleton. The Journal of rheumatology. 2009 Mar 1;36(3):609-13.

17. Neugebauer V, Han JS, Adwanikar H, Fu Y, Ji G. Techniques for assessing knee joint pain in arthritis. Molecular pain. 2007 Mar 28;3:1744-8069.

18. McQueen FM, Doyle A, Dalbeth N. Imaging in goutWhat can we learn from MRI, CT, DECT and US?. Arthritis research \& therapy. $2011 \mathrm{Dec} ; 13(6): 246$.

19. Dalbeth N, McQueen FM. Use of imaging to evaluate gout and other crystal deposition disorders. Current opinion in rheumatology. 2009 Mar 1;21(2):124-31.

20. Hall MC, Selin G. Spinal involvement in gout: a case report with autopsy. JBJS. 1960 Mar 1;42(2):341-3. 


\begin{tabular}{|c|c|c|c|}
\hline \multicolumn{4}{|c|}{ AUTHORSHIP AND CONTRIBUTION DECLARATION } \\
\hline Sr. \# & Author(s) Full Name & Contribution to the paper & Author(s) Signature \\
\hline 1 & Ramesh Kumar & $\begin{array}{l}\text { Literature review, Concept, } \\
\text { Final approval. }\end{array}$ & \\
\hline 2 & Asim Rehmani & $\begin{array}{l}\text { Conceptualization, write up, } \\
\text { data collection, literature } \\
\text { review, Proof reading. }\end{array}$ & \\
\hline 3 & Qazi M. Zeeshan & $\begin{array}{l}\text { Literature review, Data } \\
\text { collection, write up, analysis, } \\
\text { Proof reading. }\end{array}$ & \\
\hline 4 & Atiq Ahmed Khan & $\begin{array}{l}\text { Data collection, write up, } \\
\text { analysis, literature review. }\end{array}$ & \\
\hline 5 & Shiraz Ahmed Gauri & $\begin{array}{l}\text { Data collection, literature } \\
\text { review, initial write up. }\end{array}$ & \\
\hline 6 & Muhammad Faiq & $\begin{array}{l}\text { Write up, analysis, literature } \\
\text { review. }\end{array}$ & \\
\hline 7 & M. Sheraz Raza & $\begin{array}{l}\text { Corresponding author, } \\
\text { literature review. }\end{array}$ & \\
\hline
\end{tabular}

